$\xi=-1$

\title{
Optimisation of Gallic Acid and Quercetin Extraction from Phyllanthus Niruri
}

\author{
Suok Ling Nguang ${ }^{1}$, Yi Ling Yeong ${ }^{2}$, Sook Fun Pang ${ }^{3}$ and Jolius Gimbun ${ }^{1 *}$ \\ ${ }^{1}$ Centre of Excellence for Advanced Research in Fluid Flow (CARIFF), Universiti Malaysia Pahang, 26300 Gambang, Pahang, MA- \\ LAYSIA. \\ ${ }^{2}$ Faculty of Chemical \& Natural Resources Engineering, Universiti Malaysia Pahang, 26300 Gambang, Pahang, MALAYSIA. \\ ${ }^{3}$ Faculty of Industrial Science and Technology, Universiti Malaysia Pahang, 26300 Gambang, Pahang, MALAYSIA. \\ *Corresponding author: jolius@ump.edu.my
}

\begin{abstract}
This paper presents an optimization study of gallic acid and queretin extraction from Phyllanthis niruri by using response surface methodology. Gallic acid and quercetin was extracted with the aid of sonication and the polyphenols content was analyzed using Ultra Performance Liquid Chromatography (UPLC). The effect of extraction time, amplitude and ethanol concentration on the yield of gallic acid and quercetin were investigated. The optimum gallic acid yield $(10.43 \pm 0.28 \mathrm{mg} \mathrm{GA} / \mathrm{g} \mathrm{DW})$ was found in ethanol concentration of $40.0 \%$, extraction time of 15 minutes and amplitude of $86.85 \%$ after solving the regression equation. Meanwhile, the optimum condition to obtain the highest yield of quercetin $(17.48 \pm 0.21 \mathrm{mg}$ Que/g DW) was found in ethanol concentration of $40.0 \%$, extraction time of 15 minutes and amplitude of $75 \%$. The findings in this work may serve as a useful guide to obtain highest extraction yield of gallic acid and quercetin from Phyllanthus niruri.
\end{abstract}

Keywords: Phyllanthus niruri; ultrasonic assisted extraction; gallic acid; quercetin; response surface methodology; UPLC.

\section{Introduction}

Phyllanthus niruri ver. name Dukung anak (Family: Phyllanthaceae) is a widespread tropical herb that having a smooth bark on the ascending branches with the height of $50-70 \mathrm{~cm}$ tall. It is found mainly in wet rainforest conditions and spreads rapidly throughout the tropical and subtropical countries such as Malaysia, Indonesia, Thailand, Nigeria, Brazil, and India. P. niruri was commonly used as a traditional medicine due to its well-known curative properties. For example, in India, $P$. niruri is a common herb used to heal sickness related to genitourinary system. $P$. niruri extracts had been investigated with the ability to restrict the hepatitis B virus growth, antifungal properties, anti-viral and hypoglycemic action for liver disease treatment [1]. $P$. niruri also has a diuretic property which allowed to be used in urinary tract infections. In addition, the active constituents from $P$. niruri also exhibit anticancer, antioxidant and anti-inflammatory properties by the presence of valuable polyphenols [2]-[3].

The most important factor that affects the yield and recovery of the bioactive components from plant materials is the extraction method. The previous extraction method performed was soxhlet extraction, the extraction time consumed up to 3 hours to obtain $150 \mathrm{ml}$ volume of extract [4]. Another method of extraction performed by [5] was maceration that consumes 10 hours for the extraction process. Both the aforementioned extraction methods were the conventional and traditional method which normally required elevated temperature and longer duration. Furthermore, elevated temperature may cause the thermal degradation of the polyphenol due to the heat exposure for a prolonged period [6].
For instance, vitamin A and E, polyphenols and antioxidant suffer from thermal degradation after exposure to high temperature for a period of time [7]-[8]. Extraction process with a shorter residence time and operating at a mild temperature $\left(<70{ }^{\circ} \mathrm{C}\right)$ is preferable in order to minimize the thermal degradation of bioactive components during the extraction. Hence, ultrasonic assisted extraction (UAE) was chosen in this work because it operates at a mild temperature besides the sonication enhances both the bulk and inner mass transfer thus enhancing extraction yield and reducing extraction time. To our knowledge, limited study related to optimization of UAE parameters for extraction of $P$. niruri polyphenols, and hence this is the aims of the current work.

\section{Material and Method}

\subsection{Chemicals and Plant Material}

Ethanol, HPLC grade dimethyl sulfoxide, aluminium hexachloride, 2,2-diphenyl-1-picrylhydrazyl were obtained from Sigma Aldrich (St Louis, MO). P. niruri similar to that with a voucher specimen deposited in the Herbarium of Rimba Ilmu, Institute of Science Biology, University of Malaya, Kuala Lumpur (voucher number KLU46618) were purchased from Malaysia Herbal Shop, Selangor, Malaysia. The dried plant was crushed into powder. The powder was kept in an airtight plastic bag in a desiccator at room temperature to prevent moisture absorption prior to the experiment.

\subsection{Ultrasonic Assisted Extraction(UAE)}


UAE was carried out using a sonicator Q700 with a probe of $13 \mathrm{~mm}$ tip diameter. The solvent to plant solid ratio was fixed to 2 wt.\%, throughout this work based on our one parameter at time study. The upper and lower bound of all the parameters in the twolevel factorial study was set based on the literature and the limitation of the equipment. The two-level factorial (2LF) study was performed with three independent variables, namely, ethanol concentration (X1), time (X2) and amplitude (X3). There are two dependent variables: Gallic acid (Y1) and Quercetin (Y2). A total of 8 experiment points was carried out. Subsequently, optimization of the independent variable was performed according to central composite design (CCD).

\subsection{UPLC Quantification of Polyphenols}

Polyphenols from $P$. niruri extract such as quercetion and gallic acid was determined and quantified by Waters Acquity UPLC $\mathrm{H}-$ Class (Milford, MA) fitted with UPLC C18 Column $(2.1 \times 75 \mathrm{~mm}$, $1.8 \mu \mathrm{m})$ and UPLC C18 column guard $(2.1 \times 5 \mathrm{~mm}, 1.8 \mu \mathrm{m})$. The UPLC system is equipped with photodiode array detector and connected to a computer running Water Empower 2 software. The eluent system consists of A $(0.1 \%$ formic acid in $\mathrm{H} 2 \mathrm{O})$ and $\mathrm{B}$ $(0.1 \%$ formic acid in acetonitrile $)$ at a flow rate of $0.3 \mathrm{ml} / \mathrm{min}$. The gradient elution: $0-5 \mathrm{~min}, 30 \% \mathrm{~B} ; 5-10 \mathrm{~min}, 30-40 \% \mathrm{~B} ; 10-15 \mathrm{~min}$, $40-50 \% \mathrm{~B} ; 15-35 \mathrm{~min}, 50-95 \% \mathrm{~B} ; 35-45 \mathrm{~min}, 95-5 \%$ B. The column is maintained at room temperature and he injection volume of $2 \mu \mathrm{l}$ was set for each sample. The sample is filtered using the 0.2 $\mu \mathrm{m}$ nylon membrane filter before injection to UPLC system. The peak of quercetin and gallic acid was detected at $\lambda=350 \mathrm{~nm}$.

\subsection{Validation Experiment}

The optimum condition that gave the highest yield of gallic acid and quercetin within the range of the factor studied was obtained from the optimization study via response surface methodology (RSM). Verification was performed by running experiment according to the optimum conditions obtained from RSM and the actual response is compared to the predicted response from the model.

\section{Results and Discussion}

\subsection{UPLC Quantification of Gallic Acid and Quercetin}

Previous method employed to analyze active components from $P$. niruri was HPLC [9 - 11], with an analysis time to achieve active component separation ranging from 32 to 45 minutes. A faster quantification method is always desired to reduce the overall analysis time. In this work, UPLC which offers a faster separation was employed to $P$. niruri polyphenols for the first time. Figure 1 shows the UPLC chromatogram of $P$. niruri extract. The chromatogram showed a good separation for both gallic acid and quercetin. Active components were identified by comparing both retention time and UV spectra of the authentic standard and extract as shown in (Figs. 1 to 3). The retention time and UV spectra of both the standard and plant extracts show a good match, thus confirming the presence of gallic acid and quercetin. Quantification of active components was measured by comparing the peak areas from the extract and with the calibration curve developed using an authentic standard. The calibration curve of quercetin and gallic acid showed good linearity $(\mathrm{r} 2=0.998)$ for the concentration range from 0.005 to $0.5 \mathrm{~g} / \mathrm{ml}$. The analysis time using UPLC method in this work is about 20 minutes, which is faster than other reported methods such as 32 minutes [12], 40 minutes [10] and 45 minutes [13].

\subsection{Effect of Solvent Type to the Polyphenols Extrac- tion}

Solvent type is the one of the factors affecting the extraction of the polyphenol. The yield of polyphenol extraction using solvent of different polarities such as water, $20 \%$ ethanol, $40 \%$ ethanol, $60 \%$ ethanol, $80 \%$ ethanol, $100 \%$ ethanol, $20 \%$ isopropanol, $40 \%$ isopropanol, $60 \%$ isopropanol, $80 \%$ isopropanol and $100 \%$ isopropanol was studied for UAE. In order to get a fair comparison, all extractions were carried out at the equivalent solid to solvent ratio. Solvent polarity and its structural characteristic affect the solubility of bioactive components in a different solvent. It was found that highly methoxylated compounds such as quercetin, which is a lipophilic compound shows good stability in lower polarity solvent [5], [14]. Similarly, [15] reported that the amount of sinensetin and eupatorin, which is highly methoxylated compounds, found to be extracted at higher extracted amount at lower polarity solvent, isopropanol extract.

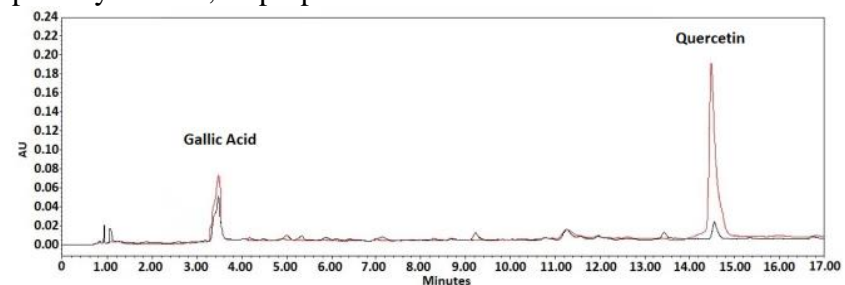

Fig. 1: Identification of active compound by comparing retention time.
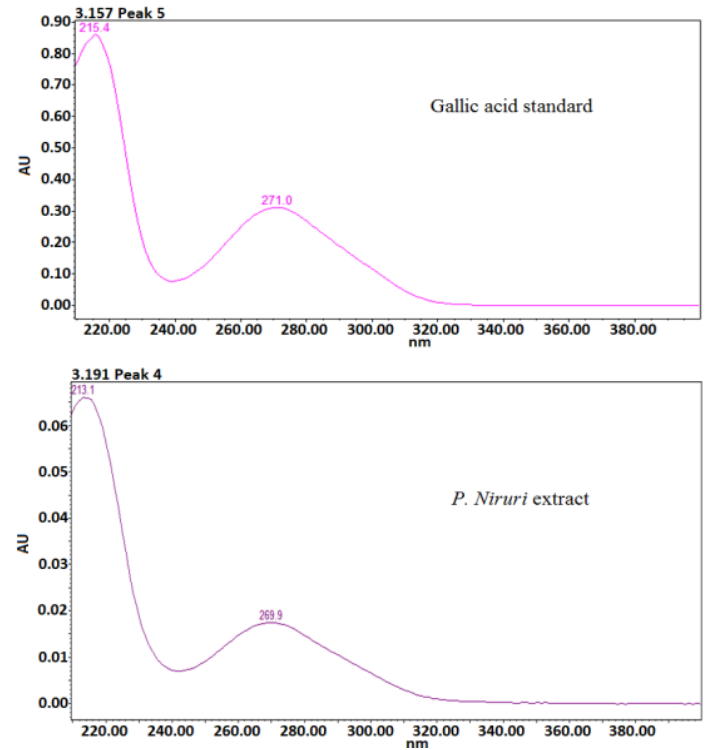

Fig. 2: Identification of gallic acid by matching UV spectra of sample to standard in Empower software library.
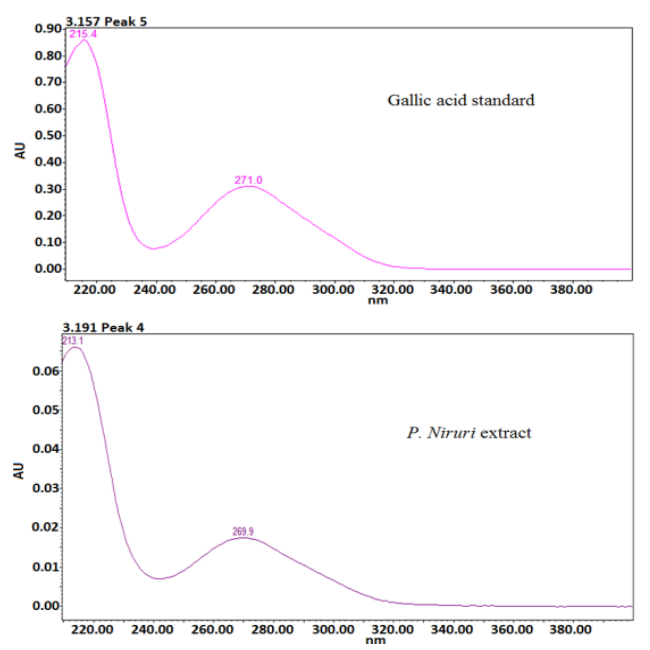

Fig. 3: Identification of quercetin by matching UV spectra of sample to standard in Empower software library. 
On the other hand, a highly hydroxylated compound such as gallic acid, which is hydrophilic is much easily soluble in water. Result from this work shows that gallic acid has the higher extraction yield in water compared to quercetin. The result in Table I shows that aqueous alcoholic solvent (20\% of either ethanol and isopropanol) has a higher simultaneous extraction yield of both gallic acid (13.19 mg GA/g DW) and quercetin (10.14mg Que/g DW) compared to pure solvent such as $100 \%$ ethanol, $100 \%$ isopropanol and pure water. The results suggest that the polarity of the solvents used affect the efficiency of the polyphenol extraction. The result shows that, a mixture of lower and high polarity solvent produced a higher extraction yield of both target components. For instance, solvent with a lower polarity index such as the isopropyl alcohol has a better efficiency to extract a wider range of phenolic content [16]. The major components present in Phyllanthus species is active hydrolyzable tannins that can be extracted using the ethanol-water mixture as the components are semipolar compounds such as ellagitannins and gallotannins [17], which is in good agreement to the result obtained in this work.

Table 1: Effect of Solvent on Polyphenols Extraction from Phyllanthus niruri

\begin{tabular}{|l|l|l|}
\hline Solvent & $\begin{array}{l}\text { Gallic Acid }(\mathbf{m g ~ G A} / \mathbf{g} \\
\text { DW) }\end{array}$ & $\begin{array}{l}\text { Quercetin }(\mathbf{m g} \text { Que/g } \\
\text { DW) }\end{array}$ \\
\hline Ethanol & $0.99 \pm 0.088$ & $7.34 \pm 0.730$ \\
\hline Isopropanol & $1.26 \pm 0.011$ & $8.55 \pm 0.843$ \\
\hline Water & $15.44 \pm 2.436$ & $3.19 \pm 0.539$ \\
\hline 20\% Ethanol & $13.19 \pm 0.368$ & $10.14 \pm 4.519$ \\
\hline 40\% Ethanol & $9.86 \pm 0.125$ & $5.48 \pm 0.314$ \\
\hline 60\% Ethanol & $9.20 \pm 0.102$ & $6.12 \pm 0.206$ \\
\hline $80 \%$ Ethanol & $4.42 \pm 0.221$ & $6.74 \pm 1.148$ \\
\hline $\begin{array}{l}\text { 20\% Isopropa- } \\
\text { nol }\end{array}$ & $3.06 \pm 0.336$ & $9.10 \pm 2.545$ \\
\hline $\begin{array}{l}40 \% \text { Isopropa- } \\
\text { nol }\end{array}$ & $2.67 \pm 0.323$ & $8.50 \pm 1.437$ \\
\hline $\begin{array}{l}\text { 60\% Isopropa- } \\
\text { nol }\end{array}$ & $2.34 \pm 1.190$ & $9.63 \pm 1.128$ \\
\hline $\begin{array}{l}\text { 80\% Isopropa- } \\
\text { nol }\end{array}$ & $2.21 \pm 0.139$ & $8.45 \pm 0.455$ \\
\hline
\end{tabular}

\subsection{Factorial Analysis of UAE}

A $2^{5-1}$ factorial design with three parameters were studied for UAE. 8 experiments were tabulated for UAE factorial design. Fractional factorial experimental design and the result for UAE was tabulated in Table 2. Response was analysed by examining the model fitting, interpreting the model graphically, finding the optimum point, and performing a model validation.

\subsubsection{Effect of Solvent concentration, Time and Amplitude}

The effect of solvent concentration, time and amplitude on the polyphenol extraction yield is summarized in Table 2 . The solvent concentration ranged from $20 \%$ to $80 \%$, time ranged from 3 minutes to 9 minutes and amplitude ranged from $20 \%$ to $90 \%$ were studied in the factorial design.

Table 2: Experimental Design and Response for Factorial Analysis of UAE.

\begin{tabular}{|c|c|c|c|c|c|}
\hline \multirow{2}{*}{$\begin{array}{l}\mathrm{R} \\
\mathrm{u} \\
\mathrm{n}\end{array}$} & \multicolumn{3}{|l|}{ Factors } & \multicolumn{2}{|l|}{ Responses } \\
\hline & $\begin{array}{l}\text { EtOH } \\
\text { concen- } \\
\text { tration } \\
(\%)\end{array}$ & $\begin{array}{l}\text { Time } \\
\text { (min) }\end{array}$ & $\begin{array}{l}\text { Ampli- } \\
\text { tude } \\
(\%)\end{array}$ & $\begin{array}{l}\text { Gallic Acid } \\
\text { (mg GA/g } \\
\text { DW) }\end{array}$ & $\begin{array}{l}\text { Quercetin } \\
\text { (mg Que/g } \\
\text { DW) }\end{array}$ \\
\hline 1 & 80 & 9 & 90 & 4.009 & 97.825 \\
\hline 2 & 80 & 9 & 20 & 2.803 & 84.179 \\
\hline 3 & 20 & 3 & 90 & 3.784 & 88.273 \\
\hline 4 & 20 & 3 & 20 & 2.672 & 78.72 \\
\hline 5 & 20 & 9 & 20 & 3.624 & 93.731 \\
\hline 6 & 20 & 9 & 90 & 4.62 & 101.919 \\
\hline 7 & 80 & 3 & 20 & 1.705 & 69.168 \\
\hline 8 & 80 & 3 & 90 & 3.188 & 84.179 \\
\hline
\end{tabular}

Table 3 and Table 4 show the percentage contributions of each factor on the yield of extraction for gallic acid and quercetin. The main factor $\mathrm{A}, \mathrm{B}$ and $\mathrm{C}$ played the major contribution in the gallic acid and quercetin extraction, which contributes more than $90 \%$ compared to the interactive factors. The suggested best condition for main factor in UAE to maximize gallic acid and quercetin yield are at $20 \%$ ethanol concentration, 9 minutes extraction time and $90 \%$ amplitude. The optimum condition was achieved by setting the ethanol concentration, time and amplitude in range, whereas maximising the gallic acid and quercetin yield. The desirability of the optimum solution is 0.998 , which is closer to the maximum value of 1.0 , indicating that the solution is close to the optimum condition for both gallic acid and quercetin extraction. Three experimental runs were performed on the optimum point obtained from the two-level factorial study. It was found that the predicted (from two-level factorial) and actual response (experiment) are in good agreement with deviation of less than $10 \%$. The result indicates that the optimisation model based on two-level factorial study is sufficiently accurate to predict the gallic acid and quercetin extraction yield. It was found from $2 \mathrm{LF}$ analysis that, none of the factors $\mathrm{A}, \mathrm{B}$, and $\mathrm{C}$ has a combined interactive effect on the yield of gallic acid and quercetin.

Table 3: Sum of Squares and The Percent Contribution Of Each Factor For Gallic acid.

\begin{tabular}{|l|l|l|l|}
\hline Factor & $\begin{array}{l}\text { Effect Esti- } \\
\text { mate }\end{array}$ & $\begin{array}{l}\text { Sum of } \\
\text { Squares }\end{array}$ & $\begin{array}{l}\text { \% Contribu- } \\
\text { tion }\end{array}$ \\
\hline $\begin{array}{l}\text { A-EtOH Concentra- } \\
\text { tion }\end{array}$ & -2.360 & 11.140 & 43.440 \\
\hline B-Time & 1.890 & 7.160 & 27.830 \\
\hline C-Amplitude & 1.840 & 6.840 & 26.590 \\
\hline AB & -0.240 & 0.110 & 0.440 \\
\hline AC & -0.480 & 0.460 & 1.780 \\
\hline BC & 0.056 & 0.006 & 0.024 \\
\hline
\end{tabular}

Table 4: Sum of Squares and the Percent Contribution of Each Term for Quercetin.

\begin{tabular}{|l|l|l|l|}
\hline Factor & $\begin{array}{l}\text { Effect Esti- } \\
\text { mate }\end{array}$ & $\begin{array}{l}\text { Sum of } \\
\text { Squares }\end{array}$ & $\begin{array}{l}\text { \% Contribu- } \\
\text { tion }\end{array}$ \\
\hline $\begin{array}{l}\text { A-EtOH Concentra- } \\
\text { tion }\end{array}$ & -15.33 & 469.82 & 14.48 \\
\hline B-Time & 21.76 & 946.94 & 29.18 \\
\hline C-Amplitude & 28.27 & 1597.99 & 49.23 \\
\hline AB & -3.28 & 21.54 & 0.66 \\
\hline AC & 3.37 & 22.77 & 0.70 \\
\hline BC & -9.03 & 162.99 & 5.02 \\
\hline
\end{tabular}

Table 5: Comparison between the Predicted and Experimental Value for Optimum Condition from 2LF.

\begin{tabular}{|l|l|l|l|l|}
\hline Response & Run & $\begin{array}{l}\text { Predicted } \\
\text { Value }\end{array}$ & $\begin{array}{l}\text { Experimental } \\
\text { Value }\end{array}$ & $\begin{array}{l}\text { Error } \\
(\%)\end{array}$ \\
\hline $\begin{array}{l}\text { Gallic Acid } \\
\text { (mg GA/g DW) }\end{array}$ & $\begin{array}{l}\text { Run } \\
1\end{array}$ & 8.231 & 8.215 & 0.195 \\
\cline { 2 - 5 } & $\begin{array}{l}\text { Run } \\
2\end{array}$ & 8.231 & 7.596 & 8.36 \\
\cline { 2 - 5 } & $\begin{array}{l}\text { Run } \\
3\end{array}$ & 8.231 & 7.574 & 8.674 \\
\hline $\begin{array}{l}\text { Quercetin } \\
\text { (mg Que/g DW) }\end{array}$ & $\begin{array}{l}\text { Run } \\
1\end{array}$ & 90.926 & 91.085 & 0.175 \\
\cline { 2 - 5 } & $\begin{array}{l}\text { Run } \\
2\end{array}$ & 90.926 & 89.448 & 1.652 \\
\cline { 2 - 5 } & $\begin{array}{l}\text { Run } \\
3\end{array}$ & 90.926 & 92.891 & 2.115 \\
\hline
\end{tabular}

\subsection{Experimental Design of UAE optimization}

A CCD with a total of 20 experiments which include 7 runs for factorial design, 7 runs for axial points and 6 repetitive runs at the central point were performed. The CCD experimental design and responses is shown in Table 6 . The values of regression coefficients were calculated, the response variable and the test variables were fitted to the second-order polynomial equation. The model equation in coded form is given as follows:

Gallic acid $=7.75+0.65 \mathrm{~A}+1.11 \mathrm{~B}+0.30 \mathrm{C}+0.33 \mathrm{AB}$

$-0.18 \mathrm{AC}+0.26 \mathrm{BC}+0.25 \mathrm{~A}^{2}+0.29 \mathrm{~B}^{2}-0.34 \mathrm{C}^{2}$ 
Gallic acid $=13.59+1.60 \mathrm{~A}+0.44 \mathrm{~B}-0.25 \mathrm{C}+0.43 \mathrm{AB}$

$-0.53 \mathrm{AC}-0.67 \mathrm{BC}-0.10 \mathrm{~A}^{2}-0.25 \mathrm{~B}^{2}+0.06 \mathrm{C}^{2}$

\subsection{Effect of Ethanol Concentration, Extraction Time and Amplitude in Polyphenol Extraction}

The effect of the three factors, i.e., ethanol concentration, extraction time and amplitude on gallic acid and quercetin extraction were analysed using RSM. Result from the experiment is shown tin Table 6. Three-dimensional response surface and contour plot were generated to study the interactive effect of the variables to the response. The effect of non-interaction factors ethanol concentration (A), time (B) and amplitude (C) on polyphenol extraction is depicted in Figure 4 for both gallic acid and quercetin. The interactive effects have $p$-value higher than 0.10 indicating that interaction between the factors is not significant to the response. The result obtained from CCD study agrees to the two-level factorial analysis.

Table 6: Experimental Design and Response for UAE Optimization.

\begin{tabular}{|c|c|c|c|c|c|}
\hline $\begin{array}{c}\mathrm{R} \\
\text { un }\end{array}$ & $\begin{array}{c}\text { Ethanol concen- } \\
\text { tration (\%) }\end{array}$ & $\begin{array}{c}\text { Time } \\
(\mathrm{min})\end{array}$ & $\begin{array}{c}\text { Ampli- } \\
\text { tude (\%) }\end{array}$ & $\begin{array}{c}\text { Gallic } \\
\text { Acid }\end{array}$ & Quercetin \\
\cline { 5 - 6 } & & & & $\begin{array}{c}\text { (mg GA/g } \\
\text { DW) }\end{array}$ & $\begin{array}{c}\text { (mg } \\
\text { Que/g } \\
\text { DW) }\end{array}$ \\
\hline 1 & 48.5 & 11.00 & 82.50 & 8.207 & 14.996 \\
\hline 2 & 15.0 & 15.00 & 75.00 & 7.214 & 14.569 \\
\hline 3 & 27.5 & 11.00 & 95.11 & 6.114 & 14.043 \\
\hline 4 & 27.5 & 11.00 & 82.50 & 7.524 & 19.092 \\
\hline 5 & 27.5 & 17.73 & 82.50 & 10.254 & 16.139 \\
\hline 6 & 40.0 & 7.00 & 75.00 & 8.125 & 14.954 \\
\hline 7 & 27.5 & 11.00 & 82.50 & 7.414 & 16.994 \\
\hline 8 & 27.5 & 11.00 & 82.50 & 8.820 & 18.645 \\
\hline 9 & 27.5 & 11.00 & 69.89 & 6.365 & 14.741 \\
\hline 10 & 15.0 & 15.00 & 90.00 & 8.781 & 14.269 \\
\hline 11 & 27.5 & 4.27 & 82.50 & 5.786 & 15.053 \\
\hline 12 & 27.5 & 11.00 & 82.50 & 8.082 & 19.616 \\
\hline 13 & 27.5 & 11.00 & 82.50 & 7.937 & 17.875 \\
\hline 14 & 40.0 & 7.00 & 90.00 & 7.948 & 18.433 \\
\hline 15 & 15.0 & 7.00 & 75.00 & 6.044 & 14.635 \\
\hline 16 & 6.5 & 11.00 & 82.50 & 7.598 & 18.422 \\
\hline 17 & 27.5 & 11.00 & 82.50 & 6.898 & 18.388 \\
\hline 18 & 15.0 & 7.00 & 90.00 & 7.465 & 12.931 \\
\hline 19 & 40.0 & 15.00 & 75.00 & 9.737 & 18.113 \\
\hline 20 & 40.0 & 15.00 & 90.00 & 11.500 & 15.711 \\
\hline
\end{tabular}

Table 7: Condition for factors for optimum polyphenol extraction

\begin{tabular}{|l|l|l|}
\hline Factor & Gallic Acid & Quercetin \\
\hline Ethanol concentration (\%) & 40 & 40 \\
\hline Extraction time (min) & 15 & 15 \\
\hline Amplitude (\%) & 86.85 & 75 \\
\hline Extraction yield (mg/g DW) & 10.07 & 17.78 \\
\hline Desirability & 0.825 & 0.888 \\
\hline
\end{tabular}

The relationship between the response and experimental variables is shown in Figure 4. It can be observed that longer extraction time (>13 min) and higher sonication amplitude (ranging from 80 to $87 \%$ ) gave a higher yield of gallic acid. Higher ethanol concentration (40\%) is also favorable for gallic acid extraction. Quercetin extraction also favors longer extraction time (>13 $\mathrm{min})$ and higher ethanol concentration (40\%), in a similar manner to that of gallic acid. However, the best sonication amplitude for quercetin extraction is lower (75 to $78 \%$ ) than that of gallic acid. Earlier, Nguang et al. [18] also found that $40 \%$ aqueous ethanol yielded the highest yield of total polyphenol and total flavonoid from P. niruri.

The optimum parameter to obtain the highest yield of gallic acid and quercetin was determined from the model equation with the condition of all the parameters is kept in range. Only one response is optimized at a time. The optimum condition for gallic acid extraction was found in ethanol concentration of $40 \%$, extraction time of $15 \mathrm{~min}$ and sonication amplitude of $86.85 \%$ with the yield of gallic acid of $10.07 \mathrm{GA} / \mathrm{g}$ DW as shown in Table 6. Meanwhile, the optimum condition for quercetin extraction was found in etha- nol concentration of $40 \%$, extraction time of $15 \mathrm{~min}$ and sonication amplitude of $75 \%$ with the yield of gallic acid of 17.78 GA/g DW. The desirability for gallic acid and quercetin optimization is close to unity with the value of 0.825 and 0.888 , respectively (Figure 5). The model is considered good since the desirability exceeds 0.8 .

The suitability of the model equation to predict the desired response (gallic acid and quercetin yield) is tested experimentally using the optimum conditions described in Table 7. The result of the verification using triplicate run is presented in Table 8 . The deviation between the predicted and measured responses was ranging from $0.14 \%$ to $4.74 \%$. The experimental values were in good agreement with the predicted values of the model with an error less than $5 \%$, which proved adequacy of the model for predicting the optimum yield of gallic acid and quercetin from UAE.
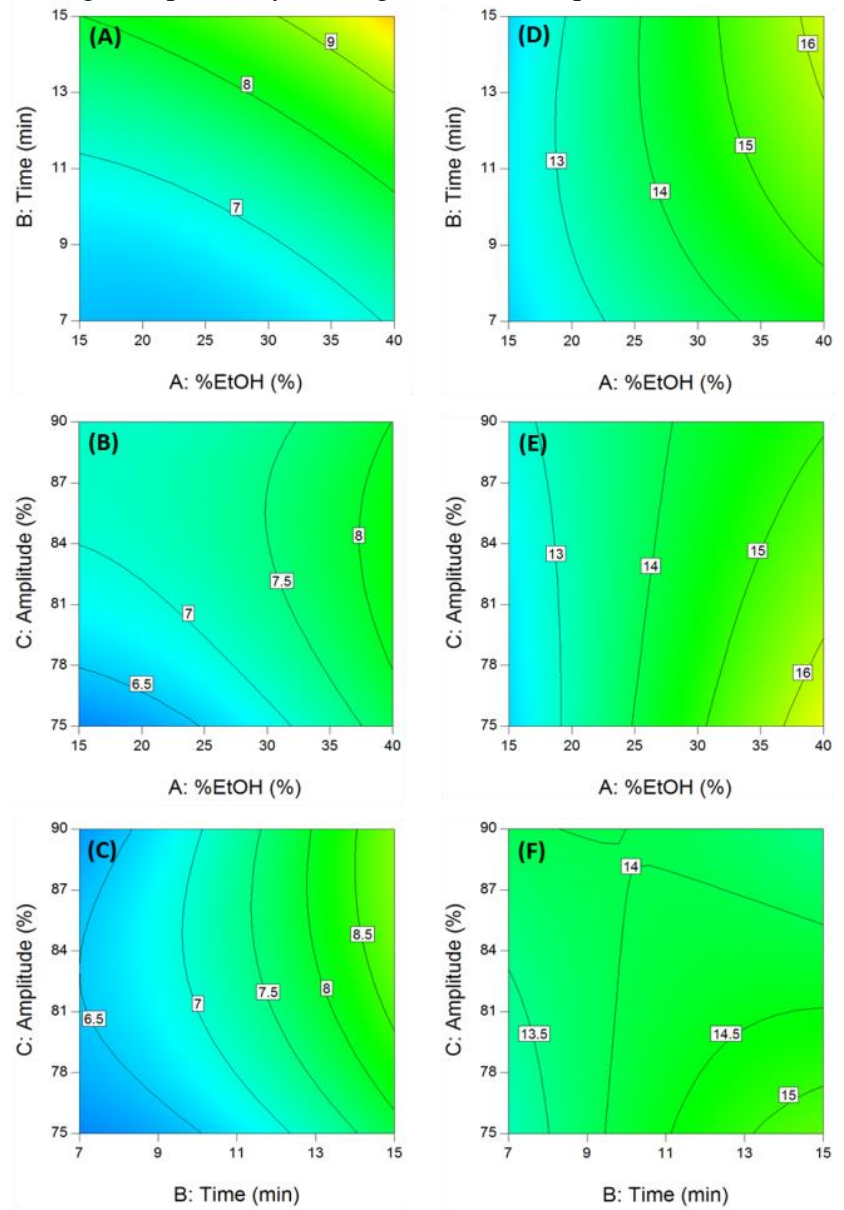

Fig. 4: Contour plot for gallic acid and quercetin extraction from $P$. niruri. Gallic acid (A, B, C). Quercetin (D, E, F).
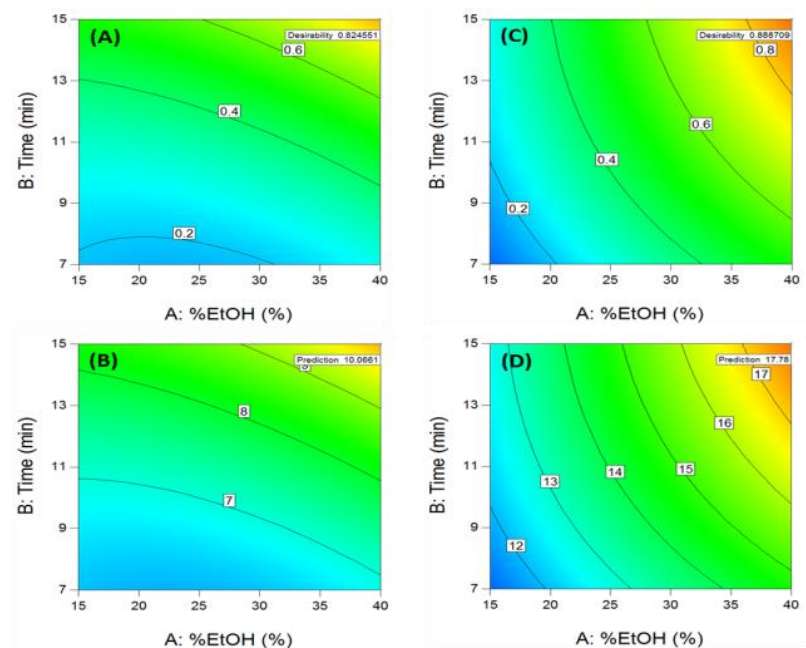

Fig. 5: Optimum extraction point for gallic acid (A, B) and quercetin (C, D) 
Table 8: Validation of the predicted optimum point

\begin{tabular}{|l|l|l|l|l|}
\hline \multirow{2}{*}{ Response } & Run & $\begin{array}{l}\text { Predicted } \\
\text { Value }\end{array}$ & $\begin{array}{l}\text { Experimental } \\
\text { Value }\end{array}$ & $\begin{array}{l}\text { Error } \\
(\%)\end{array}$ \\
\hline \multirow{5}{*}{ Gallic Acid } & Run 1 & 10.498 & 10.103 & 3.91 \\
\cline { 2 - 5 } & Run 2 & 10.498 & 10.706 & 1.943 \\
\cline { 2 - 5 } & Run 3 & 10.498 & 10.468 & 0.287 \\
\hline \multirow{3}{*}{ Quercetin } & Run 1 & 17.212 & 17.524 & 1.78 \\
\cline { 2 - 6 } & Run 2 & 17.212 & 17.692 & 2.713 \\
\cline { 2 - 6 } & Run 3 & 17.212 & 17.236 & 0.139 \\
\hline
\end{tabular}

\section{Conclusion}

The optimum condition for gallic acid extraction can be obtained using ethanol concentration $40 \%$, extraction time of 15 minutes and amplitude of $86.85 \%$ after solving the regression equation. Under the optimum condition, the gallic acid yield was $10.426 \pm$ $0.28 \mathrm{mg} \mathrm{GA} / \mathrm{g}$ DW. Meanwhile, the optimum condition for quercetin extraction was found at ethanol concentration $40 \%$, extraction time 15 minutes and amplitude $75 \%$, which gave a quercetin yield of $17.484 \pm 0.208 \mathrm{mg}$ Que/g DW.

\section{Acknowledgement}

Research funding from the Ministry of Higher Education Malaysia FRGS/1/2016/TK02/UMP/02/4 managed by Research and Innovation Department UMP (RDU160124) and Universiti Malaysia Pahang (PGRS 170302). Dr. Pang Sook Fun is the recipient of UMP Post-Doctoral Fellowship in Research.

\section{References}

[1] Boim MA, Heilberg IP \& Schor B (2010), Phyllanthus niruri as a promising alternative treatment for nephrolithiasis. Int Braz J Urol 36(6), 657-664.

[2] Xia Y, Luo H, Liu JP \& Gluud C (2011), Phyllanthus species for chronic hepatitis B virus infection Cochrane Database Syst Rev 13(4) doi: 10.1002/14651858.CD008960.pub2.

[3] Sharma P, Parmar J, Verma P, Sharma P \& Goyal PK (2009), Antitumor activity of Phyllanthus niruri (a medical plant) on chemicalinduced skin carcinogenesis in mice. Asian Pac J Cancer Prec 10(6), pp 1089-1094

[4] Markom M, Hasan M, Daud WRW, Singh H \& Jahim JM (2007), Extraction of hydrolysable tannins from Phyllanthusniruri linn: Effects of solvents and extraction methods. Separation and Purification Technology 52(3), 487-96.

[5] Franco J, Sineiro M, Rubilar M, Sanchez M, Jerez M, Pinelo M \& Nunez MJ (2008), Polyphenols from plant materials:extraction and antioxidant power. Electronic Journal of Environment, Agriculture and Food Chemistry 7, 3210-3216.

[6] Pang SF, Yusoff MM \& Gimbun J (2014), Assessment of phenolic compounds stability and retention during spray drying of Orthosiphon stamineus extracts. Food Hydrocolloids 37, 159-65.

[7] Muhamad N, Yusoff MM \& Gimbun J (2015), Thermal degradation kimetic of nocotinic acid, pantothenic acid and catechin derived from Averrhoa bilimbi fruits.RSC Advances 5, 74132-74137.

[8] Mercali GD, Jaeschke DP, Tessaro IC \& Marczak LDF (2013), Degradation kinetics of anthocynins in acerola pulp: Comparison between ohmic and conventional heat treatment. Food Chemistry 136, 853-857.

[9] Murugaiyah V, \& Chan KL (2007), Analysis of lignans from Phyl lanthus niruri $L$. in plasma using a simple HPLC method with fluorescence detection and its application in a pharmacokinetic study. Journal of Chromatography 852, 138-144.

[10] Cuoto AG, Kunzler M, Spaniol B, Magalhaes P, Ortega G \& Petrovick P (2013), Chemical and technological evaluation of the Phyllanthus niruri aerial parts as a function of cultivation and harvesting conditions. Brazilian Journal of Pharmacognosy 23(1), pp. 36-43.

[11] Ghosal S, Veeraragavan M \& Kalidindi SR (2013), U.S. Patent No. 20130122119A1. New Brunswick. DC: U.S Patent and Office Trademark Office.

[12] Annamalai A, \& Lakshimi PTV (2009), HPTLC and HPLC Analysis of Bioactive Phyllanthin from Different Organs of Phyllanthus amarus. Asian Journal of Biotechnology 1(4), 154-162.
[13] Tripathi AK, Verma RK, Gupta AK, Gupta MM \& Khanuja SP (2006), Quantitative determination of phyllanthinand hypophyllantin in phyllanthus species by high-performance thin layer chromatography. Phytochemistry Analysis 17(6), 394-397.

[14] Metrouh-Amir H, Durte CM \& Maiza F (2015), Solvent effect on total phenolic contents, antioxidant, and antibacterial activities of Matricaria pubescens. Industrial Crops and Product 67, 249-256.

[15] Pang SF, Lau MJ, Yusoff MM \& Gimbun J (2017), MicrowaveIrradiation Induced Fast Simultaneous Extraction of Methoxylated and Hydroxylated Phenolic Compounds from Orthosiphon stamineus Leaves. Materials Science Forum 890, 155-158.

[16] Poh-Hwa T, Yoke-Kqueen C, Indu Bala J \& Son R (2011), Bioprotective properties of three Malaysia Phyllanthus species: An investigation of the Antioxidant and Antimicrobial Activities. International Food Research Journal 18, 887-893.

[17] Tian F, Li B, Ji BP, Yang JH, Zhang GZ, Chen Y \& Luo YC (2009), Antioxidant and antimicrobial activities of consecutive extracts from Galla chinesis: The polarity effects the bioactivities. Food Chemistry 113, 173-179.

[18] Nguang SL, Yeong YL, Pang SF \& Gimbun J (2016), Ultrasonic Assisted Extraction on Phenolic and Flavonoid Content from Phyllanthus niruri Plant. Indian Journal of Science and Technology 10(2), 1-5. 